\title{
Meningkatkan Keterampilan Servis Atas Dalam Permainan Bola Voli dengan Pendekatan Pembelajaran Drill
}

Zailan Taslim

SDN 132 Rejang Lebong

zailantaslim27@gmail.com

\begin{abstract}
This study aims to find out about the ability or skills of class $V$ students of elementary school 132 Rejang Lebong in servicing volleyball can be improved through the learning method of drill. In accordance with these problems, this study uses Classroom Action Researchw hich is carried out in two cycles and in that cycle there are planning, action, observation/reflection, and reflection. The sample/subject of this study were students at elementary school 132 Rejang Lebong, totaling 19 students. In the final test, collect data from cycle 1 and cycle 2 using the service skill test instrument for volleyball. From several inter-cycle test result obtained learning outcomes data from cycle 1 and cycle 2 there has been an increase of between $40 \%$ to $90 \%$. Based on the result of data analysis and discussion it can be concluded that the drill and play approach can improve the ability to service volleyball at elementary school 132 Rejang Lebong. It is recommended that sports educators can implement the drill and play approach, as they are proven to able to improve service learning outcomes for volleyball.
\end{abstract}

Keyword: Service, volleyball, drill.

\section{Pendahuluan}

Pembaharuan dalam pengertian pendidikan adalah suatu upaya untuk menghubungkan keadaan saat ini dan keadaan di masa mendatang, dengan menerapkan program kurikulum dan metode pembelajaran yang baru, sesuai dengan perkembangan dunia pendidikan yang cenderung mengutamakan efisiensi dan efektifitas (Wijaya, 1998: 2).

Pendidikan jasmani memiliki banyak cabang olahraga permainan, salah satu materi pokok yang termasuk di dalamnya yaitu bola voli. Adapun manfaat dari bermain bola voli yaitu untuk membentuk sikap tubuh yang baik meliputi anatomis, fisiologi, kesehatan, kebugaran, dan kemampuan jasmani.

Teknik dasar bermain bola voli yaitu servis, pas (passing), umpan (set-uper), smash, dan bendungan (block). Servis merupakan salah satu teknik bermain bola voli. Menurut Falid dan Hidayat (2016: 114), teknik bermain bola voli dilakukan bertujuan untuk menunjang pemain agar dalam melakukan permainan bola voli dapat menghasilkan permainan yang indah. Sehingga, teknik dasar servis harus bisa dikuasai. Hal ini sependapat dengan Lubis dan Agus (2017: 6) yang menyimpulkan bahwa terjadi peningkatan hasil belajar pas (passing) atas bola voli melalui penerapan variasi pembelajaran pada siswa kelas VIII di SMP Negeri 1 Aek Sonsongan Asahan pada Tahun Ajaran 2016/2017. 
Dalam bermain bola voli, pendekatan pembelajaran sangat berperan dalam pelaksanaan proses pembelajaran. Adapun pendekatan pembelajaran yang bisa dilakukan untuk peningkatan keterampilan servis bola voli yaitu pendekatan drill.

Metode drill adalah pembelajaran yang melakukan kegiatan secara berulang-ulang, yang bertujuan untuk memperkuat keterampilan agar menjadi permanen. Menurut penelitian yang dilakukan oleh Yusmar (2017: 151), permainan bola voli yang dilakukan melalui modifikasi permainan dapat meningkatkan kemampuan keterampilan teknik bermain bola voli pada siswa kelas X di SMAN 2 Kampar. Penelitian lain yang dilakukan oleh Muzaffar (2015: 53) juga menunjukkan bahwa ada peningkatan hasil belajar siswa melalui model pembelajaran (passing) atas dengan pola pendekatan bermain pada pendidikan jasmani.

Pembelajaran passing atas dalam bola voli melalui permainan sasaran tembak dapat meningkatkan kualitas dan hasil belajar siswa kelas V di SDN Sidamulya 01 Kabupaten Tegal Tahun 2014 (Wibowo, 2015: 2043). Iskandar dan Yulianingsih (2015: 169) menunjukkan bahwa penggunaan metode bermain melalui media bola plastik dapat meningkatkan keterampilan passing atas pada permainan bola voli. Penelitian lain yang dilakukan oleh Juniardi dan Redno (2019: 50), juga menunjukkan bahwa melalui teknik permainan 3 on 3 membuat siswa merasa senang serta gembira dalam bermain voli, sehingga dapat meningkatkan keterampilan teknik passing atas pada permainan bola voli.

Berdasarkan data hasil belajar siswa pada pembelajaran servis atas bola voli kelas $\mathrm{V}$ SDN 132 Rejang Lebong, dari 19 siswa yang dinilai, sebanyak 8 siswa atau 22\% tuntas dan 22 orang siswa atau 78\% tidak tuntas. Hal ini disebabkan sebagian besar siswa masih kurang memahami teknik servis atas bola voli. Selain itu, siswa kurang aktif melakukan latihan, sehingga ini menyebabkan hasil belajar siswa yang diperoleh rendah.

Dalam penelitian ini, untuk meningkatkan keterampilan servis atas dalam permainan bola voli, maka peneliti menggunakan pendekatan drill dalam proses pembelajaran. Hal ini dilakukan karena pendekatan drill merupakan pembelajaran secara berulang, sehingga proses pembelajaran akan terlaksana secara maksimal dan tujuan pembelajaran akan tercapai.

Penelitian lain yang mendukung penelitian ini yaitu dilakukan oleh Alwijaya (2018: 183), yang mengungkapkan bahwa penggunaan metode drill dalam proses pembelajaran bola voli menunjukkan hasil yang maksimal, dengan peningkatan pada siklus II hingga 90\%. Penelitian serupa juga dilakukan oleh Iskandar (2016: 21), bahwa dengan menggunakan pendekatan pembelajaran drill dapat meningkatkan hasil belajar passing bawah dalam permainan bola voli.

Identifikasi masalah dalam penelitian ini yaitu: (1) sebagian siswa kurang konsentrasi dalam mengikuti pelajaran, (2) siswa masih kurang memahami materi pembelajaran, (3) siswa tidak dapat menjawab pertanyaan guru, (4) kesempatan bertanya yang diberikan oleh guru tidak dimanfaatkan siswa, (5) metode yang digunakan guru tidak membuat siswa untuk belajar mengalami langsung, dan (6) dalam menyampaikan materi, guru tidak menggunakan pendekatan keterampilan yang tepat.

\section{Metode}

Penelitian ini merupakan Penelitian Tindakan Kelas (Classroom Action Research), yaitu penelitian yang bertujuan untuk memperbaiki proses dan meningkatkan hasil pembelajaran. Penelitian tindakan kelas ini terdiri dari dua 
siklus, masing-masing siklus terdiri dari dua kali pertemuan. Setiap siklus terdiri dari beberapa tahapan-tahapan, yaitu perencanaan, tindakan, observasi dan refleksi. Subjek penelitian yaitu siswa kelas V SDN 132 Rejang Lebong yang berjumlah 19 orang.

Instrumen penelitian terdiri dari lembar observasi siswa, lembar observasi guru, dan lembar tes keterampilan servis atas bola voli. Instrumen lembar observasi siswa digunakan untuk mengetahui aktivitas siswa selama mengikuti proses pembelajaran. Observasi ini dilakukan oleh peneliti. Instrumen observasi guru ditujukan untuk mengetahui aktivitas guru selama proses pembelajaran, yang dilakukan oleh teman sejawat. Instrumen lembar tes keterampilan servis atas bola voli berisi komponen-komponen penilaian terhadap gerak keterampilan servis atas dalam permainan bola voli yang dilakukan siswa.

Teknik pengumpulan data dalam penelitian ini yaitu pengamatan (observasi) dan tes. Pengamatan (observasi) digunakan untuk mengungkapkan aktivitas siswa dan guru selama proses pembelajaran belangsung, sedangkan tes dalam penelitian ini digunakan untuk mengukur kemampuan siswa dalam proses pembelajaran. Analisis data dan intreprestasi data terhadap data yang berhasil dikumpulkan dalam pelaksanaan penelitian tindakan ini dapat dilakukan sepanjang proses penelitian, karena penelitian tindakan adalah penelitian yang bersifat dialektik, yaitu meliputi perencanaan, tindakan yang diserta dengan pengumpulan data, dilanjutkan dengan analisis dan interprestasi data, perencanaan baru, tindakan dan pengumpulan data, analisis dan interprestasi data lagi dan seterusnya

\section{Hasil}

\section{Siklus I}

Siklus I dilaksanakan dalam dua pertemuan. Pada pertemuan 1, rata-rata kemampuan siswa dalam melakukan servis atas dalam permainan bola voli adalah 67,9\% dengan kategori cukup. Pada pertemuan 2, rata-rata kemampuan siswa dalam melakukan servis atas dalam permainan bola voli adalah $74,8 \%$ dengan kategori baik. Pada pertemuan I, kemampuan servis atas siswa mengalami peningkatan, dari 67,9\% dengan kategori cukup meningkat menjadi 74,8\% dengan kategori baik pada pertemuan 2 .

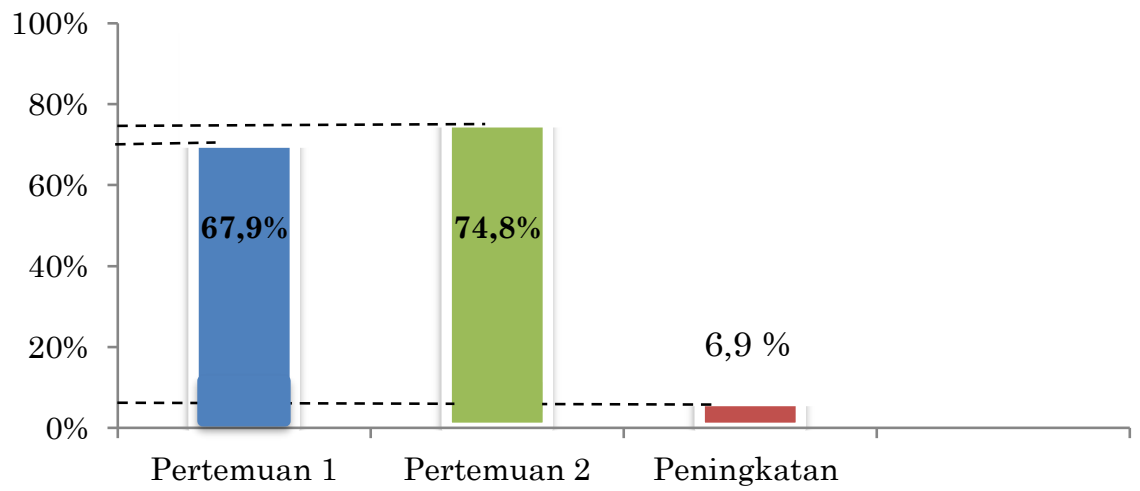

Grafik 1. Hasil penilain kemampuan servis atas siklus I

Selanjutnya, berdasarkan lembar observasi aktivitas guru pada siklus I, dapat diketahui bahwa guru memperoleh skor 8 dengan kategori baik. Dalam hal ini, aktivitas yang dilakukan oleh guru, siswa belum memperhatikan guru saat diadakan absensi dan belum mendengarkan koreksi guru sebelum doa dan membubarkan diri. 
Siklus II

Siklus II dilaksanakan dalam dua pertemuan. Pada pertemuan 1, rata-rata kemampuan siswa dalam melakukan servis atas dalam permainan bola voli adalah 82,9\% dengan kategori baik. Pada pertemuan 2, rata-rata kemampuan siswa dalam melakukan servis atas dalam permainan bola voli adalah 93\% dengan kategori baik. Pada pertemuan I, kemampuan servis atas siswa mengalami peningkatan, dari $82,9 \%$ dengan kategori cukup meningkat menjadi 93\% dengan kategori baik pada pertemuan 2 .

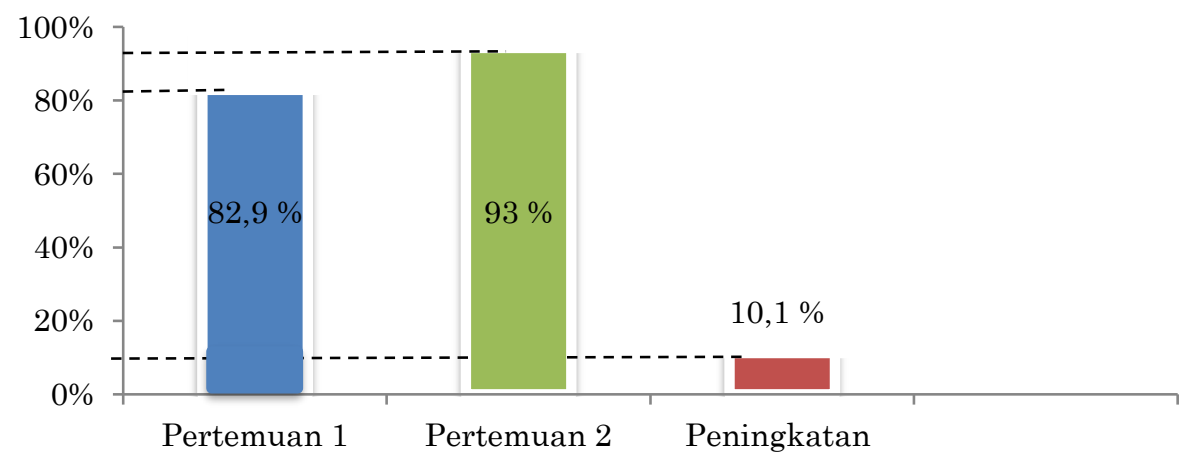

Grafik 2. Hasil penilaian kemampuan servis atas bola siklus II

Selanjutnya, berdasarkan lembar observasi aktivitas guru pada siklus II, semua penilaian aktivitas guru telah terlaksana dan guru memperoleh skor 10 dengan kategori sangat baik.

\section{Pembahasan}

Berdasarkan hasil penelitian pada siklus I dan II, diketahui bahwa melalui pedekatan pembelajaran drill dan bermain dapat meningkatkan keterampilan servis atas dalam permainan bola voli pada siswa kelas V SDN 132 Rejang Lebong.

Pada siklus I, terdapat kekurangan-kekurangan dan kelemahan-kelemahan, sehingga perlu diadakan perbaikan-perbaikan dalam proses pembelajaran pada siklus II secara sistematis. Hal utama yang dilakukan guru adalah memperbaiki pendekatan pembelajaran yang digunakan.

Pada siklus II, dengan desain pembelajaran yang lebih baik ternyata dapat memperbaiki dan meningkatkan proses pembelajaran pada servis atas dalam permainan bola volli. Hal ini dapat terlihat dari penilaian proses siswa siklus I yaitu $67,9 \%$ meningkat menjadi $74,8 \%$ dan siklus II yaitu $82,9 \%$ meningkat menjadi $93 \%$. Lembar observasi pada aktivitas guru siklus I yaitu angka 8 dengan kriteria baik meningkat menjadi angka 10 dengan kriteria sangat baik pada siklus II.

Tabel 8. Perbandingan Keterampilan Servis Atas antar Siklus

\begin{tabular}{|c|c|c|c|c|c|}
\hline \multicolumn{3}{|c|}{ Siklus 1 } & \multicolumn{3}{c|}{ Siklus 2 } \\
\hline $\begin{array}{c}\text { Pertemuan } \\
1\end{array}$ & $\begin{array}{c}\text { Pertemuan } \\
2\end{array}$ & Peningkatan & Pertemuan & Pertemuan & Peningkatan \\
\hline $67,9 \%$ & $74,8 \%$ & $6,9 \%$ & $82,9 \%$ & $93 \%$ & $10,1 \%$ \\
\hline
\end{tabular}

Hasil pengamatan dalam penelitian ini menunjukkan bahwa adanya peningkatan dalam proses pembelajaran di setiap siklus. Hal ini telah sesuai dengan pelaksanaan penelitian tindakan kelas yang bertujuan untuk 
memperbaiki proses pembelajaran. Hasil tes servis atas dalam permainan bola voli yang dilakukan oleh siswa menunjukkan bahwa ada peningkatan hasil pembelajaran dalam penelitian ini.

Hasil penelitian ini menunjukkan bahwa dengan menggunakan pendekatan drill dalam poses pembelajaran dapat meningkatkan keterampilan sevis atas dalam permainan bola voli, seperti yang ditunjukkan pula dalam penelitian Nugroho (2015), bahwa dengan menggunakan latihan drill dalam kegiatan ekstrakurikuler bola voli dapat meningkatkan kemampuan passing atas hingga 76,66\%. Penelitian lain yang dilakukan oleh Ilsam (2017), juga menunjukkan bahwa terdapat pengaruh yang signifikan metode drill terhadap kemampuan service atas pada siswa SMP 15 Kendari, dengan nilai signifikansi 0,001 $<0,05$ dengan rata-rata pretes 9,55 dan post-tes 10,88 .

\section{Simpulan}

Berdasarkan hasil penelitian, dapat disimpulkan bahwa proses pembelajaran PJOK dengan pedekatan pembelajaran drill dapat meningkatkan kemampuan servis atas dalam permainan bola voli pada siswa kelas V SDN 132 Rejang Lebong. Pendekatan drill yang dilakukan dalam pembelajaran yaitu proses yang dilakukan secara berulang-ulang, sehingga keterampilan siswa dapat terasah secara maksimal.

Peningkatan hasil pembelajaran pada siklus I pertemuan 1 yaitu 67,9\% meningkat menjadi $74,8 \%$ pada pertemuan 2 dan siklus II pada pertemuan 1 yaitu $82,9 \%$ meningkat menjadi $93 \%$ pada pertemuan 2 . Lembar observasi pada aktivitas guru siklus I yaitu angka 8 dengan kriteria baik meningkat menjadi angka 10 dengan kriteria sangat baik pada siklus II.

Setelah melaksanakan penelitian ini, peneliti menyarankan bagi guru PJOK agar dapat menerapkan berbagai metode pembelajaran selama proses pembelajaran berlangsung, sehingga peserta didik tidak merasakan kebosanan dan dapat menerima pembelajaran secara maksimal. Metode pembelajaran bermain dan pendekatan drill dapat digunakan pada proses pembelajaran servis atas bola voli.

\section{Referensi}

Alwijaya, M. E. (2018). Penerapan Metode Drill untuk Meningkatkan Hasil Belajar Passing Bawah Bola Voli Siswa Kelas VII.A SMP Negeri 2 Batukliang Tahun Pelajaran 2016/2017. Jurnal Ilmiah Mandala Education (Jime), 4, $172-184$.

Falid, C. \& Hidayat, T. (2016). Pengaruh Latihan Drill Berpola Terhadap Peningkatan Keterampilan Underhand Pass Bolavoli (Studi pada Ekstrakurikuler Siswa Putra Bolavoli SMP N 3 Sidayu). Jurnal Pendidikan Olahraga dan Kesehatan Universitas Negeri Surabaya, 04, 113-117.

Iisam. (2017). Pengaruh Metode Mengajar Drill dan Metode Mengajar Konvensional dalam Meningkatkan Keterampilan Servis Atas pada Permainan Bola Voli Siswa SMPN 15 Kendari. Wakapendik, 1, 1-9.

Iskandar \& Yulianingsih. (2015). Peningkatan Keterampilan Passing Atas dalam Permainan Bola Voli Melalui Metode Bermain Siswa Kelas VIII SMP Negeri 3 Sungai Ambawang Kabupaten Kubu Raya. Jurnal Pendidikan Olahraga, 4, 157-169.

Iskandar, M. I. (2017). Upaya Meningkatkan Hasil Belajar Passing Bawah Bola Voli Mini dengan Menggunakan Pendekatan Pembelajaran Drill pada Siswa Kelas V SD Negeri 1 Jungke Karanganyar Tahun Ajaran 2016 . Jurnal Ilmiah Spirit, 17, 15-23. 
Juniadi, A. \& Redno, R. (2019). Upaya Meningkatkan Keterampilan Passing Atas Bola Voli dengan Menggunakan Permainan 3 On 3 pada Kelas VII. 4 di Smp Negeri 21 Kota Bengkulu. Multilateral: Jurnal Pendidikan Jasmani dan Olahraga, 18, 46-50.

Lubis, A. E \& M. Agus. 2017. Peningkatan hasil belajar passing atas pada permainan bola voli melalui variasi pembelajaran siswa SMP. Jurnal Pendidikan jasmani Indonesia, 13, 58-64.

Muzaffar, Ahmad. (2015). Model Pembelajaran (Passing) Atas Bola Voli dengan Pola Pendekatan Bermain pada Pendidikan Jasmani. Jurnal Cerdas Sifa, 1, 4654.

Nugroho, A. J. 2015. Latihan Metode Drill untuk Meningkatkan Kemampuan Passing Atas Bola Voli Peserta Ekstrakurikuler Bola Voli di SD Negeri Genito Windusari Kabupaten Magelang. Universitas Negeri Yogyakarta.

Wibowo, D. H. 2015. Pembelajaran Passing Atas Bola Voli Melalui Permainan Sasaran Tembak. Journal of Physical Education, Sport, Health and Recreations, 4, 2040-2045.

Wijaya. 1998. (SBM) Strategi Belajar Mengajar. Bandung: Pustaka Setia.

Yusmar, A. (2017). Upaya Peningkatan Teknik Permainan Bola Voli Melalui Modifikasi Permainan Siswa Kelas X SMA Negeri 2 Kampar. Jurnal Pendidikan dan Pengajaran Program Studi Pendidikan Guru Sekolah Dasar FKIP Universitas Riau, 1, 143-152. 